\title{
La inoculación de Pinus greggii con el hongo ectomicorrícico Laccaria laccata favorece a las comunidades nativas de rizobacterias promotoras del crecimiento vegetal
}

\author{
Pinus greggii inoculation with the ectomycorrhizal fungi Laccaria laccata enhances native population of \\ plant-growth-promoting rhizobaceria
}

\begin{abstract}
Maryeli Aguirre-Zamoraa, Jesús Pérez-Morenoa, Nguyen Esmeralda López-Lozanob, José Luis Barragán Soriano ${ }^{a}$ y Julián Delgadillo-Martínez ${ }^{\text {a* }}$

a Colegio de Postgraduados, Campus Montecillo. Edafología, Área de Microbiología. Km. 36.5 Carretera Federal MéxicoTexcoco, Montecillo, Texcoco, Estado de México. C.P. 56230.

b División de Ciencias Ambientales, Instituto Potosino de Investigación Científica y Tecnológica A.C. Camino a la Presa San José No. 2055. Col. Lomas 4a. Secc. San Luis Potosí, San Luis Potosí. C.P. 78216.
\end{abstract}

\section{RESUMEN}

La simbiosis pino-hongo ectomicorrícico es de gran importancia ecológica debido a la interacción microbiana establecida en la micorrizósfera y a las condiciones edáficas favorables creadas por la descomposición de la materia orgánica. El objetivo de este trabajo fue estimar el efecto de la colonización del hongo ectomicorrícico Laccaria laccata sobre el crecimiento de Pinus greggii, así como la abundancia de microorganismos en sus raíces, en condiciones de invernadero. Para lo cual se realizó con un diseño experimental completamente al azar, compuesto por dos tratamientos: $P$. greggii inoculado con L. laccata y testigo. Se evaluó la actividad metabólica microbiana (AMM), diversidad metabólica microbiana, altura, peso seco, abundancia de bacterias fijadoras de nitrógeno y solubilizadoras de fosfatos. Por medio de ANOVA se observó que, un año después de la siembra y 6 meses después de la inoculación, L. laccata mejoró el crecimiento de $P$. greggii; además, aumentó la AMM, mas no se presentaron diferencias en la diversidad respecto al testigo. También, se encontró mayor abundancia de bacterias solubilizadoras de fosfatos y fijadoras de nitrógeno en la rizósfera de las plantas inoculadas. Lo cual sugiere que estos organismos se ven favorecidos en las condiciones que propicia la presencia de L. laccatta.

Palabras clave: Pinos, Biolog EcoPlates, diversidad microbiana, solubilización de fosfatos, fijación de nitrógeno.

\section{ABSTRACT}

The pine-ectomycorrhizal symbiosis is of great ecological importance due to the microbial interaction established in mycorrhizosphere and the favorable edaphic conditions created by the decomposition of organic matter. The objective of this work was to estimate the effect of the ectomycorrhizal fungus Laccaria laccata colonization on the growth of Pinus greggii, as well as the abundance of microorganisms in its roots under greenhouse conditions. For which we used a completely randomized experimental design, composed of two treatments: P. greggii inoculated with L. laccata and con-

*Autor para correspondencia: Julián Delgadillo-Martínez

Correo electrónico: juliandm@colpos.mx

Recibido: 7 de julio del 2020

Aceptado: 13 de octubre de 2020 trol. Microbial metabolic activity (AMM), microbial metabolic diversity, height, dry weight, abundance of nitrogen-fixing and phosphate-solubilizing bacteria were evaluated. By means of ANOVA we observed that, one year after sowing and 6 months after inoculation, L. laccata improved the growth of $P$. greggii; Furthermore, the AMM increased, but there were no differences in diversity with respect to the control. Also, a greater abundance of phosphate solubilizing and nitrogen fixing bacteria was found in the rhizosphere of the inoculated plants. This suggests that these organisms are favored under the conditions propitiated by the presence of L. laccatta.

Keywords: Pines, Biolog EcoPlates, microbial diversity, phosphate solubilization, nitrogen fixation.

\section{INTRODUCCIÓN}

Los hongos ectomicorrícicos son un componente fundamental en el funcionamiento de los bosques (Baldrian, 2017), ya que favorecen la absorción de nutrientes; primordialmente $\mathrm{N}$ y $\mathrm{P}$ en suelos con baja fertilidad y contribuyen de forma significativa en el ciclo del carbono por medio de la descomposición de la materia orgánica en el suelo (Phillips et al., 2013; Shah et al., 2015). Además, ayudan a los árboles a desarrollarse en condiciones de estrés abiótico, como la sequía, y a protegerse de fitopatógenos. Debido a estos beneficios, las tecnologías de producción de árboles en vivero contemplan el establecimiento de la simbiosis árbol-hongo ectomicorrícico desde las primeras etapas fenológicas de las plantas; para que, de esta manera, se acrecienten las posibilidades de éxito de las plantas llevadas a su sitio definitivo de crecimiento. En el siglo pasado, la práctica habitual para poner en contacto a los hongos ectomicorrícicos con las plántulas era con el uso de "tierra de monte" en los sustratos (Aucina et al., 2007). De esta manera, las plántulas también se exponían a sus fitopatógenos; favoreciendo la presencia de enfermedades vegetales (Menkis et al., 2016).

Las técnicas modernas de producción de plantas en vivero incluyen el uso de sustratos solarizados o esterilizados 
junto con la inoculación (Casique et al., 2018); la cual implica la introducción de grandes cantidades de microorganismos en el suelo o sustrato y generalmente, en la proximidad de las radículas de las plántulas. Esta biotecnología permite la producción de plantas con crecimiento acelerado y resistentes ante factores bióticos y abióticos adversos habituales en los sitios a reforestar (Berruti et al., 2016). La inoculación micorrícica provoca efectos diversos de acuerdo a la especie vegetal; reportándose que las mayores posibilidades de éxito se presentan en coníferas, no-leguminosas arbustivas y pastos $\mathrm{C} 4$ (Hoeksema et al., 2010). Para acrecentar las posibilidades de éxito de la inoculación micorrícica, se recomienda conocer y manejar las principales interacciones entre los componentes de la microbiota que coloniza la rizosfera, endosfera y filosfera y, de esta manera, mejorar la sanidad vegetal y la productividad en los viveros (Vandenkoornhuyse et al., 2015; Hassani et al., 2018).

La esterilización de los sustratos, además de incrementar el crecimiento de las plantas por la eliminación de fitopatógenos, favorece el establecimiento de un microbioma diverso, representado por microorganismos benéficos (Marschner y Rumberger, 2004; Li et al., 2019). Estos microorganismos pueden ser bacterias fijadoras de nitrógeno $\mathrm{y} / \mathrm{o}$ solubilizadoras de fosfatos, controladoras de enfermedades radicales $y$, en general, promotoras del crecimiento vegetal (Troelstra et al., 2001). Con base en lo anterior, el presente trabajo tuvo como finalidad determinar el papel de la esterilización del sustrato y de la inoculación de Pinus greggii Engelm. con esporomas del hongo ectomicorrícico L. laccata en el establecimiento de diversos organismos, representados por rizobacterias benéficas para el crecimiento vegetal.

\section{MATERIALES Y MÉTODOS}

El germoplasma de $P$. greggii se colectó en el corredor de los volcanes Iztaccíhuatl y Popocatépetl, Puebla, México (límite extremo norte $98^{\circ} 40^{\prime} 18^{\prime \prime}$ y $19^{\circ} 28^{\prime} 2^{\prime \prime}$; límite extremo oeste $98^{\circ} 46^{\prime} 40^{\prime \prime}$ y $19^{\circ} 20^{\prime} 29^{\prime \prime}$; límite extremo este $98^{\circ} 37^{\prime} 28^{\prime \prime}$ y $19^{\circ} 16^{\prime} 16^{\prime \prime}$; límite extremo sur $98^{\circ} 40^{\prime} 27^{\prime \prime}$ y $19^{\circ} 14^{\prime} 36^{\prime \prime}$ ). Las semillas se esterilizaron con $30 \% \mathrm{H}_{2} \mathrm{O}_{2}$ durante 20 min. El inóculo se preparó con esporomas de L. laccata provenientes de un bosque de pinos en San Pedro Nexapa, Ozumba, Estado de México ( $19^{\circ} 8^{\prime} 12^{\prime \prime} \mathrm{N}$ y $\left.98^{\circ} 39^{\prime} 12^{\prime \prime} \mathrm{O}\right)$. Se separaron los estípites de los píleos, estos últimos se deshidrataron a $35^{\circ} \mathrm{C}$ en un horno deshidratador de tipo bandeja (Jersa ${ }^{\circ}$ ) durante 4 días. Posteriormente, se molieron en un molino eléctrico (Thomas Scientific, Modelo 4 Wiley Mill, EE.UU.) y pasó a través de un tamiz de abertura de $1 \mathrm{~mm}$ para obtener un tamaño de partícula homogéneo. El inóculo se almacenó a $5{ }^{\circ} \mathrm{C}$. El experimento se estableció en condiciones de invernadero en las instalaciones del Colegio de Postgraduados, Campus Montecillo, Estado de México.

\section{Diseño de tratamientos}

Se establecieron 2 tratamientos: 1$)$ testigo, $P$. greggii sin inocular y 2) $P$. greggii inoculado con L. laccata; en un diseño completamente al azar con 10 repeticiones.

\section{Preparación del sustrato e inoculación}

El sustrato consistió en una mezcla de arena, corteza de pino y suelo forestal en una proporción 2:2:1, se esterilizó tres veces (con un día de descanso entre cada esterilización), con vapor a una presión de $1.3 \mathrm{~kg} \cdot \mathrm{cm}^{-2}$ a $125^{\circ} \mathrm{C}$ durante 5 h. Las semillas se sembraron en tubos de plástico negro de $125 \mathrm{~cm}^{3}$ con el sustrato descrito. A las plantas del tratamiento inoculado se les adicionaron $10^{8}$ esporas de L. laccata por planta, determinada esta concentración por observación al microscopio (60X) y con hematocitómetro. Se hicieron dos inoculaciones de esporas del hongo: la primera simultáneamente con la siembra y la segunda 60 días después. Las plantas fueron regadas diariamente con agua destilada estéril, durante seis meses.

\section{Variables evaluadas \\ Altura y peso seco de las plantas}

A los 180 días después de la siembra, se cortaron las plantas y se determinó su longitud desde la base hasta la última acícula. Se colocaron en bolsas de papel y se secaron en un horno (Jersa ${ }^{\circledR}$ deshidratador de tipo bandeja, México) a $70{ }^{\circ} \mathrm{C}$, durante 3 días, para posteriormente ser pesadas en una balanza analítica (Sartorius, Entris II $1 \mathrm{mg}$ ).

\section{Perfil metabólico de comunidades microbianas}

Los perfiles metabólicos de las comunidades microbianas cultivables de ambos tratamientos (testigo e inoculado con L. laccata), se determinaron con las microplacas Biolog ${ }^{\mathrm{Tm}}$ EcoPlates (BIOLOG Inc., Hayward, CA) que contienen diferentes fuentes de carbono. Se utilizó el procedimiento adaptado de Garland y Mills (1991), posteriormente se realizaron diluciones seriadas desde $10^{-1}$ a $10^{-4}$. Se utilizó la dilución $10^{-3}$, de esta se tomó una alícuota de $150 \mu \mathrm{L}$ y se depositó en cada uno de los pocillos, en el pozo A1 únicamente se le agregó $150 \mu \mathrm{L}$ de agua destilada. Las placas se incubaron a $28^{\circ} \mathrm{C}$ y la absorbancia fue leída a $590 \mathrm{~nm}$., usando un lector de microplacas (Synergy2 MCA Bio-Tek). Las mediciones se realizaron a las $24,48,72$ y $96 \mathrm{~h}$ de la incubación.

\section{Abundancia de bacterias fijadoras de nitrógeno y solubi- lizadoras de fosfatos}

Se utilizó el procedimiento adaptado de Garland y Mills (1991) para obtener la solución madre, de la cual, realizaron diluciones seriadas de $10^{-1}$ a $10^{-6}$. Para el conteo de bacterias fijadoras de nitrógeno se utilizaron las diluciones $10^{-3}, 10^{-4}$ y $10^{-5}$, mientras que para las solubilizadoras de fosfatos se usaron $10^{-2}, 10^{-3}$ y $10^{-4}$. En ambos casos se tomaron $100 \mu \mathrm{L}$ de cada dilución y se sembraron en placas de Petri con un total de cinco repeticiones por dilución. Los medios de cultivo utilizados fueron fuente combinada de carbono y Pikovskaya para fijadoras de nitrógeno y solubilizadoras de fosfatos, respectivamente. Se incubaron por 3 y 10 días a 27 ${ }^{\circ} \mathrm{C}$, respectivamente.

Para el conteo de bacterias, en ambos medios de cultivo se seleccionó la dilución $10^{-4}$, por contener entre 30 y 300 colonias por caja de Petri. En medio Rennie se contaron 
las colonias totales, mientras que para las bacterias solubilizadoras de fosfatos se tomaron en cuenta aquellas que presentaron un halo de solubilización.

\section{Análisis estadístico}

Para el perfil metabólico de comunidades microbianas el promedio del desarrollo del color y el índice de ShannonWeaver fueron analizados por ANOVA. Todos los análisis estadísticos sobre los microorganismos se realizaron con SAS versión 9.0 para Windows (SAS Institute Inc, Cary, NC, USA).

\section{RESULTADOS Y DISCUSIÓN}

\section{Altura y peso seco de las plantas}

A los 180 días después de la siembra, las plantas del tratamiento inoculado con hongos ectomicorrícicos superaron en altura a las del testigo; con 5.4 y $3.7 \mathrm{~cm}(p<0.05)$, respectivamente. Mientras que en el peso seco se generaron valores de $0.19 \mathrm{~g}$ para el testigo y $0.37 \mathrm{~g}$ para el inoculado, como se muestra en la Figura 1. La inoculación con L. laccata aumenta el crecimiento de $P$. greggii; esto se ve reflejado en la altura y peso seco de las plantas. Un fenómeno similar en la altura de $P$. greggii fue observado por Rentería-Chávez et al. (2017), usando la misma técnica (inóculo a partir de esporomas deshidratados) y carga microbiana en la inoculación (concentración de $10^{7}$ a $10^{8}$ esporas por g de inóculo) donde, después de 12 y 24 meses de la inoculación hubo diferencias estadísticas entre el tratamiento L. laccata y el testigo, en un sustrato con las mismas proporciones usadas en este trabajo. Lo cual indica que la influencia de la inoculación sobre el crecimiento de las plantas es constante en diversos estudios. Además, las plantas inoculadas son más resistentes al cambio de las condiciones ambientales que ocurren al trasplantarlas en campo, aumentando su índice de supervivencia (Valdés, 1986; Gómez-Romero et al., 2013).

\section{Perfil metabólico de comunidades microbianas}

La diversidad metabólica microbiana, evaluada con el índice de Shannon-Weaver $\left(\mathrm{H}^{\prime}\right)$ a las 48 h de incubación, no

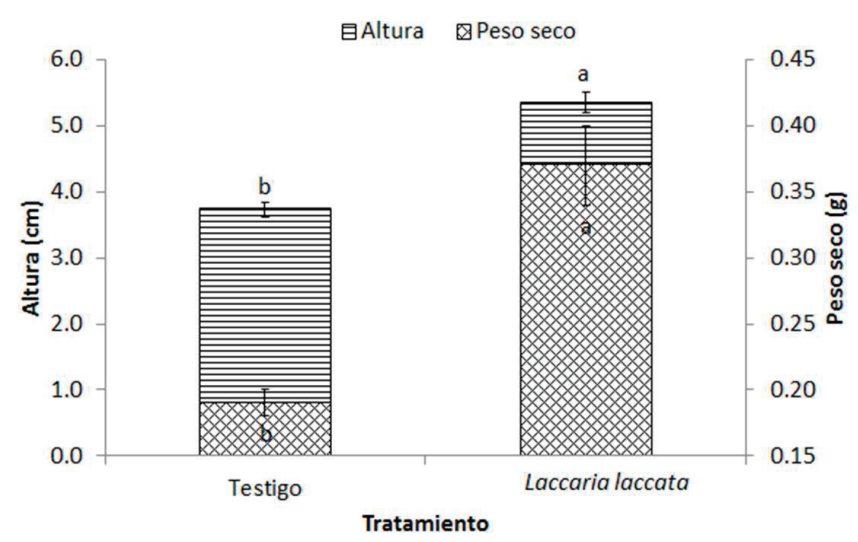

Figura 1. Altura y el peso seco de Pinus greggii en los tratamientos inoculado con Laccaria laccata y testigo sin inocular (Tukey $p<0.05$ ). Figure 1. Pinus greggii height and dry weight in Laccaria laccata - and uninoculated control groups (Tukey $\mathrm{p}<0.05$ ). mostró diferencias significativas entre tratamientos: 2.97 en el inoculado con L. laccata y 2.87 en el testigo (Figura 2a). Sin embargo, la inoculación con L. laccata afectó claramente la actividad metabólica microbiana (AMM). En general, la AMM fue mayor en el tratamiento inoculado, con una lectura de 0.3 comparada con 0.22 en el testigo, ambas a $590 \mathrm{~nm}$ (Figura 2b).

Se presentaron diferencias estadísticamente significativas entre tratamientos, para la mayoría de los grupos funcionales, a excepción de los polímeros. Para ambos tratamientos, las fuentes de carbono más utilizadas fueron las que se encuentran dentro del grupo funcional de los aminoácidos, seguidas de los carbohidratos, ácidos carboxílicos y cetónicos; mientras que las menos usadas en ambos casos, fueron los polímeros y las amidas y aminas (Figura 3).
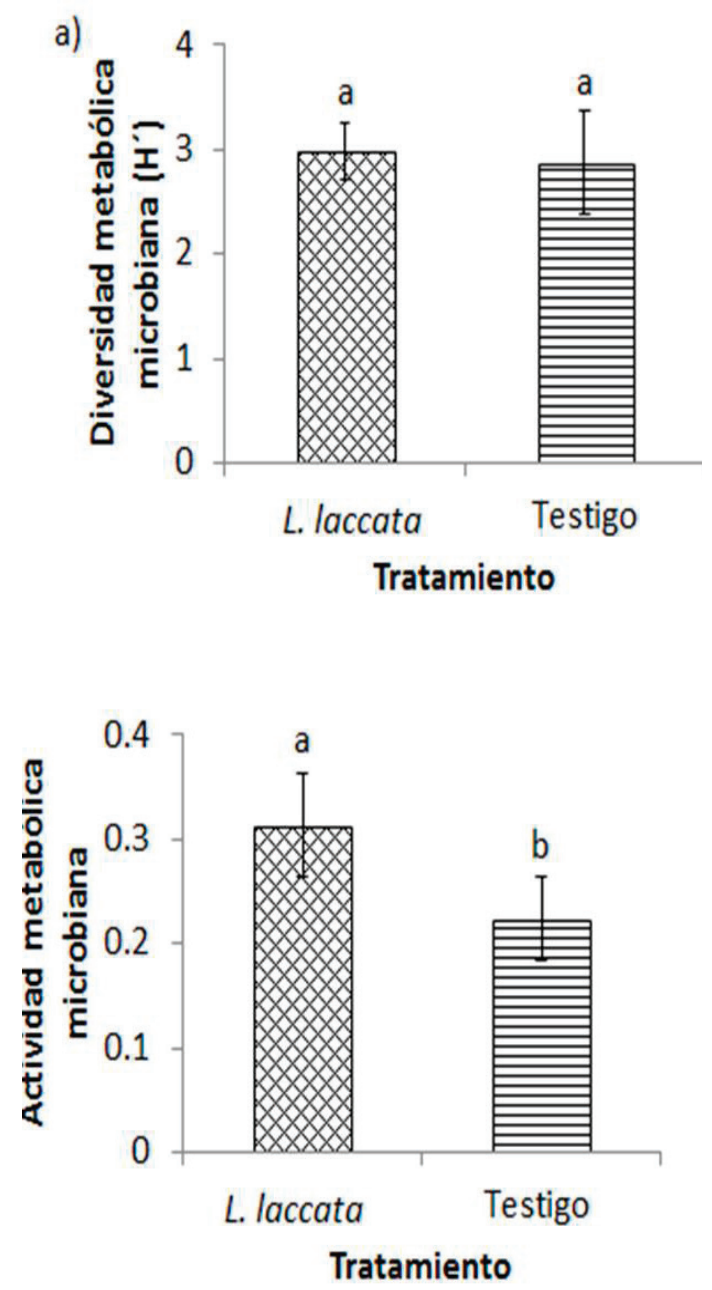

Figura 2. Diversidad $\left(\mathrm{H}^{\prime}\right)$ y actividad metabólica microbiana en la rizósfera de Pinus greggii inoculado con Laccaria laccata y en el testigo sin inocular. Letras diferentes representan diferencia estadísticamente significativa (Tukey, $a=0.05$ ).

Figure 2. Diversity $\left(\mathrm{H}^{\prime}\right)$ and microbial metabolic activity (AMM) in the rhizosphere of Pinus greggii inoculated with Laccaria laccata and in the uninoculated control. Different letters represent statistically significant difference (Tukey, $a=0.05$ ). 


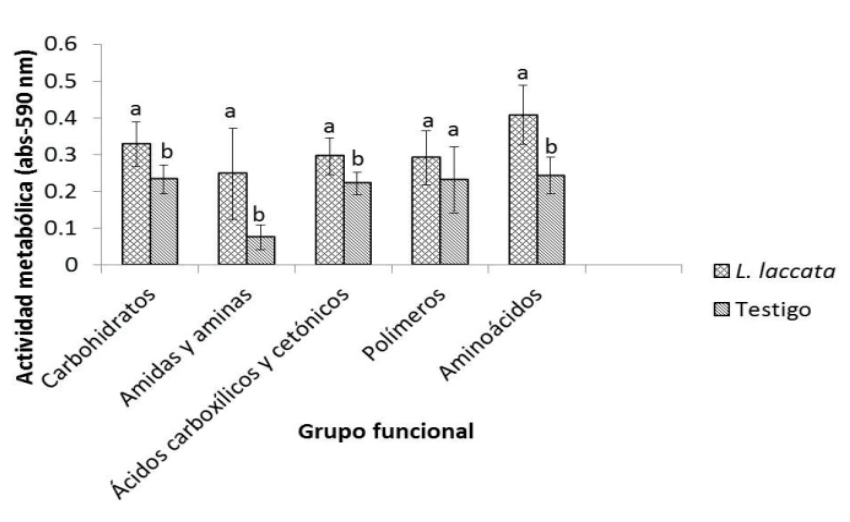

Figura 3. Actividad metabólica microbiana expresada en el uso de fuentes de carbono correspondientes a cinco grupos funcionales en la rizósfera de Pinus greggii inoculado con Laccaria laccata y en el testigo sin inocular. Letras diferentes representan diferencia estadísticamente significativa (Tukey, $a=0.05$ ).

Figure 3. Microbial metabolic activity expressed in the use of carbon sources corresponding to five functional groups in the rhizosphere of Pinus greggii inoculated with Laccaria laccata and in the uninoculated control. Different letters represent statistically significant differences (Tukey, $a=0.05$ ).

De acuerdo con Setälä (2000), las plantas ectomicorrizadas transfieren mayores cantidades de fotosintatos al suelo comparado con las no micorrizadas; lo cual se encuentra relacionado con el crecimiento de la mayoría de los microorganismos en la rizósfera. Esto coincide con los resultados del presente trabajo, donde hubo mayor abundancia de microrganismos en los pinos inoculados con L. laccata en comparación con los testigos. Además, la ectomicorriza, entre sus múltiples funciones, ayuda a la formación y descomposición de materia orgánica que puede ser aprovechada por los microorganismos rizosféricos. Esto confirma que la materia orgánica en el suelo y/o sustrato, podría mejorar el acceso a nutrientes y energía para la proliferación de biomasa microbiana, lo que conduce a que los microorganismos degraden con mayor facilidad las fuentes de carbono (Wang et al., 2019). Tian et al. (2016) mencionan que los microorganismos con la capacidad de utilizar aminoácidos como fuente de carbono, inducen cambios en la actividad peptidasa del suelo, lo que acelera la descomposición de las proteínas de la materia orgánica, agilizando la rotación de nitrógeno orgánico. Efecto que se puede observar tanto en la altura como en la producción de biomasa del pino en este experimento.

Varios estudios han demostrado que los hongos ectomicorrícicos aumentan la formación de agregados del suelo, a través de exudados fúngicos y la hidrofobicidad del micelio (Zheng et al., 2014). Esta capacidad se encuentra relacionada con la atracción de microorganismos al micelio extrarradical (Zheng et al., 2014; Viollet et al., 2017). Wang et al. (2019), observaron que la actividad metabólica microbiana de los ácidos carboxílicos, carbohidratos y amoniácidos es más elevada en los suelos que tienen mayor cantidad de agregados. Lo anterior sugiere que los hongos ectomicorrícicos no aportan dichos beneficios edáficos de manera aislada, sino en conjunto con el microbioma que se forma a partir de su inoculación. En resumen, tanto la diversidad como la actividad metabólica microbiana son indicadoras de la calidad del suelo (Wang et al., 2019). Por medio de esta información se pueden plantear estrategias de rehabilitación mediante incorporación de plantas vivas inoculadas con microorganismos adaptables al ambiente y; a su vez, realizar el seguimiento para evaluar la efectividad de la intervención (Ge et al., 2018).

\section{Abundancia de bacterias fijadoras de nitrógeno y solubi- lizadoras de fosfatos}

Dentro de los microorganismos que habitaban en ambos tratamientos, los de mayor importancia por su función, fueron las bacterias fijadoras de nitrógeno y las solubilizadoras de fosfatos. Los resultados señalaron diferencia significativa entre tratamientos, el tratamiento con inoculación tuvo mayor abundancia de bacterias fijadoras de nitrógeno que el testigo, con 90.4 y $63.2 \times 10^{5} \mathrm{UFC} \mathrm{g}^{-1}$ de suelo, respectivamente. Comportamiento similar en el caso de las bacterias solubilizadoras de fosfatos, con $7 \times 10^{5} \mathrm{UFC} \mathrm{g}^{-1}$ de suelo en el inoculado y $1.4 \times 10^{5} \mathrm{UFC} \mathrm{g}^{-1}$ en el testigo (Figura 4). Se sabe que hay un efecto positivo sobre la abundancia de bacterias cuando las plantas son ectomicorrizadas. No obstante, hay poco conocimiento acerca de los mecanismos de atracción que se llevan a cabo las raíces. Cumming et al. (2015) mencionan que se forma una comunicación tripartita (planta-hongo-bacteria), con el objetivo de mejorar el acceso a los nutrientes del suelo. Por ejemplo, la exudación de algunas sustancias orgánicas como ácido cítrico y ácido oxálico del micelio, promueve la colonización bacteriana en la micorrizósfera (Olsson y Wallander, 1998), mientras que las bacterias generan exudados como el auxofurano que estimulan el crecimiento del hongo y por ende de la planta (Cumming et al., 2015). Por ello, se dice que las raíces ectomicorrizadas influyen sobre la selección y abundancia de estas bacterias, debido a que el micelio recibe altas cantidades de carbohidratos provenientes de la fotosíntesis que realizan las plantas, lo cual genera una gran área de superficie para la colonización bacteriana (Marupakula et al., 2017).

A pesar de que las bacterias no fueron inoculadas directamente, se infiere que se encontraban en los esporomas de los hongos ectomicorrícicos al momento de su inoculación, puesto que no se realiza un proceso de desinfección a los cuerpos fructíferos, ya que esto impediría el desarrollo de ectomicorriza en las plantas. Kuppardt et al. (2018) mencionan que las raíces de las plantas seleccionan comunidades fúngicas y bacterianas que tienen efectos sobre su desarrollo y productividad. Además, algunas bacterias endófitas fijadoras de nitrógeno, como Gluconacetobacter diazotrophicus pueden encontrarse en varias especies de pinos, ayudándolos a desarrollarse en suelos pobres en este compuesto (Carrell y Frank, 2014).

Tomando en cuenta que el nitrógeno y el fósforo son los nutrientes que ocasionan mayores limitaciones en el crecimiento de las platas, parece predecible que los hongos ectomicorrícicos atraigan bacterias con la capacidad de asi- 


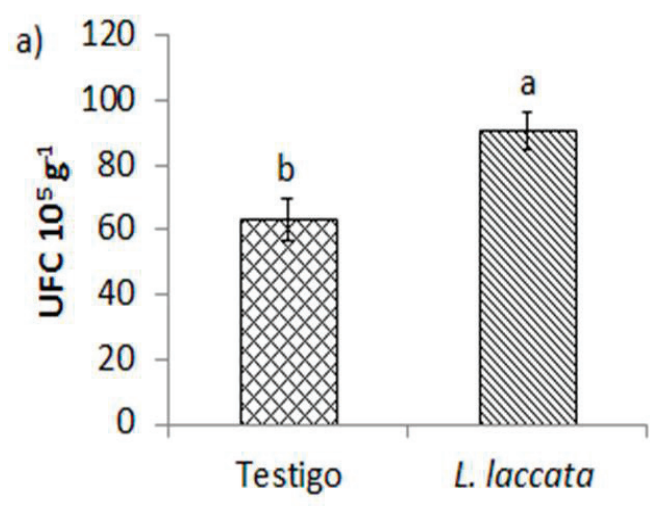

Tratamiento

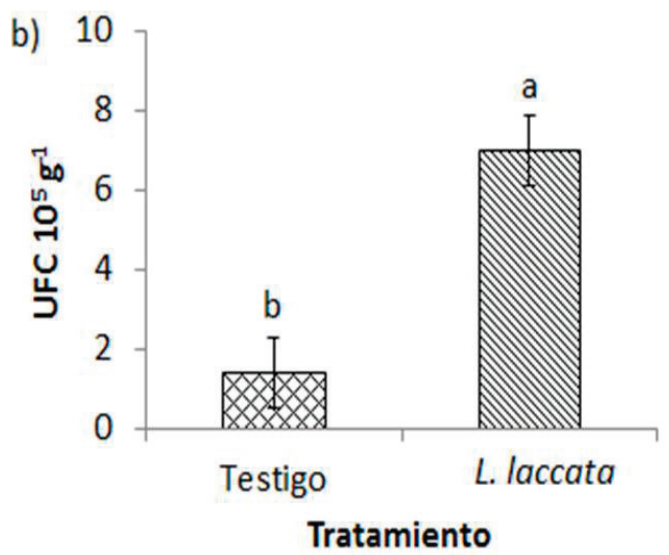

Figura 4. Tamaño de la población de bacterias solubilizadoras de fosfatos (a) y fijadoras de $\mathrm{N}$ atmosférico de vida libre (b) en la rizosfera de Pinus greggii inoculado con Lacaria laccata y en el testigo sin inocular (Tukey, a $=0.05$ ). Figure 4. Population size of phosphate solubilizing bacteria (a) and freeliving atmospheric $\mathrm{N}$-fixing (b) in the rhizosphere of Pinus greggii inoculated with Lacaria laccata and in the uninoculated control (Tukey, $a=0.05$ ).

milar dichos nutrientes. Marupakula et al. (2017) mencionan que al estudiar el microbioma asociado a las raíces de $P$. sylvestris colonizadas por diversos hongos ectomicorrícicos, algunos de los géneros representativos encontrados fueron Burkholderia y Bradyrhizobium; que tienen la capacidad de fijación de nitrógeno y/o solubilización de fosfatos (BolívarAnillo et al., 2016; Nápoles et al., 2018). Asimismo, Ekblad y Huss-Danell (1995), observaron que la influencia de la ectomicorriza aumenta la trasferencia de nitrógeno a los pinos. Esto puede indicar que, en términos generales, los hongos ectomicorrícicos atraen especies bacterianas con la facultad de promoción del crecimiento vegetal.

\section{CONCLUSIONES}

El hongo ectomicorrícico L. laccata tiene efectos positivos sobre el desarrollo de P. greggii (altura y peso seco). Además, esta simbiosis aumenta la $\mathrm{AMM}$ de la rizósfera pero no influye en la diversidad de la misma. Las fuentes de carbono más utilizadas por los microorganismos rizosféricos de $P$. greggii, sin importar la inoculación, fueron los pertenecientes a los grupos funcionales aminoácidos, carbohidratos, y ácidos carboxílicos y cetónicos; mientras que los menos usados fueron los polímeros y las aminas y amidas. La simbiosis ectomicorrícica proporciona el ambiente idóneo para la proliferación de bacterias fijadoras de nitrógeno y solubilizadoras de fosfatos, las cuales promueven el crecimiento del pino.

\section{REFERENCIAS}

Aucina, A., M. Rudawska, T. Leski, A. Skridaila, E. Riepsas y M. Iwanski. 2007. Growth and mycorrhizal community structure of Pinus sylvestris seedlings following the addition of forest litter. Applied and Environmental Microbiology. 73(15): 4867-4873.

Baldrian, P. 2017. Forest microbiome: diversity, complexity and dynamics. FEMS Microbiology Reviews. 41: 109-130.

Berruti, A., Lumini E., Balestrini, R.y Bianciotto, V. 2016. Arbuscular mycorrhizal fungi as natural biofertilizers: Let's benefit from past successes. Frontiers in Microbiology. 6:1559-103389.

Bolívar-Anillo, H.J., Contreras-Zentella, M.L. y Teherán-Sierra, L.G. 2016. Burkholderia tropica una bacteria con gran potencial para su uso en la agricultura. Tip 19: 102-108.

Carrell, A.A. y Frank, A.C. 2014. Pinus flexilis and Picea engelmannii share a simple and consistent needle endophyte microbiota with a potential role in nitrogen fixation. Frontiers in Microbiology. 5: 1-11.

Casique R., R. Mendoza, F. Galindo, S. González y S. Sánchez. 2018. Improved parameters of Pinus greggii seedling growth and health after inoculation with ectomycorrhizal fungi. Southern Forests: a Journal of Forest Science. 81(1): 1-11.

Cumming, J.R., Zawaski, C., Desai, S. y Collart, F.R. 2015. Phosphorus disequilibrium in the tripartite plantectomycorrhiza-plant growth promoting rhizobacterial association. Journal of Soil Science and Plant Nutrition. 15: 464-485.

Ekblad, A.L.F. y Huss-Danell, K.E.R.S.T.I.N. 1995. Nitrogen fixation by Alnus incana and nitrogen transfer from A. incana to Pinus sylvestris influenced by macronutrients and ectomycorrhiza. New Phytologist. 131: 453-459.

Garland, J.L. y Mills, A.L. 1991. Classification and characterization of heterotrophic microbial communities on the basis of patterns of community-level sole-carbon-source utilization. Applied and Environmental Microbiology. 57: 2351-2359.

Ge, Z., Du, H., Gao, Y. y Qiu, W. 2018. Analysis on metabolic functions of stored rice microbial communities by BIOLOG ECO microplates. Frontiers in Microbiology. 9: 1375.

Gómez-Romero, M., Villegas, J., Sáenz-Romero, C. y LindigCisneros, R. 2013. Efecto de la micorrización en el establecimiento de Pinus pseudostrobus en cárcavas. Madera y Bosques. 19: 51-63.

Hassani, M.A., Durán, P. y Hacquard, S. 2018. Microbial interactions within the plant holobiont. Microbiome. 6: 1-16.

Hoeksema, J.D., Chaudhary, V.B., Gehring, C.A., Johnson, N.C., Karst, J., Koide, R.T., Pringle, A., Zabinski, C., Bever, J.D. y Moore, J.C. 2010. A meta-analysis of context-dependency in plant response to inoculation with mycorrhizal fungi. Ecology Letters. 13:394-407.

Kuppardt, A., Fester, T., Härtig, C. y Chatzinotas, A. 2018. Rhizosphere Protists Change Metabolite Profiles in Zea mays. Frontiers microbiology. 9: 169-178.

Volumen XXIII, Número 2 
Li, K., DiLegge, M.J., Minas, I.S., Hamm, A., Manter, D. y Vivanco, J.M. 2019. Soil sterilization leads to re-colonization of a healthier rhizosphere microbiome. Rhizosphere. 12: 100176.

Marupakula, S., Mahmood, S., Jernberg, J., Nallanchakravarthula, S., Fahad, Z.A. y Finlay, R.D. 2017. Bacterial microbiomes of individual ectomycorrhizal Pinus sylvestris roots are shaped by soil horizon and differentially sensitive to nitrogen addition. Environmental Microbiology. 19: 4736-4753.

Marschner, P. y Rumberger, A. 2004. Rapid changes in the rhizosphere bacterial community structure during recolonization of sterilized soil. Biology and Fertility of Soils. 40:1-6.

Menkis, A., D. Burokienè, J. Stenlid y E. Stenström. 2016. Highthroughput sequencing shows high fungal diversity and community segregation in the rhizospheres of containergrown conifer seedlings. Forests 7(2): 44 .

Nápoles M.C., Cabrera, J.C., Wegria, G., Onderwater, R., Wattiez, R., Hernández, I. y González, G. 2018. Inducción de señales en la interacción Mesorhizobium cicerii-Cicer arietinum L. Cultivos Tropicales. 39: 101-107.

Olsson, P.A. y Wallander, H. 1998. Interactions between ectomycorrhizal fungi and the bacterial community in soils amended with various primary minerals. FEMS Microbiology Ecology. 27: 195-205.

Phillips, L.A., Ward, V. y Jones, M.D. 2013. Ectomycorrhizal fungi contribute to soil organic matter cycling in sub-boreal forests. The ISME Journal. 8: 699-713.

Rentería-Chávez, M.C., Pérez-Moreno, J., Cetina-Alcalá, V.M., Ferrera-Cerrato, R. y Xoconostle-Cázares, B. 2017. Transferencia de nutrientes y crecimiento de Pinus greggii Engelm. inoculado con hongos comestibles ectomicorrícicos en dos sustratos. Revista Argentina de Microbiología. 49: 93-104.

Setälä, H. 2000. Reciprocal interactions between Scots pine and soil food web structure in the presence and absence of ectomycorrhiza. Oecologia. 125: 109-118.
Shah, F., Nicolás, C., Bentzer, J., Ellström, M., Smits, M., Rineau, F. y Braesel, J. 2015. Ectomycorrhizal fungi decompose soil organic matter using oxidative mechanisms adapted from saprotrophic ancestors. New Phytologist. 209: 1705-1719.

Tian, J., Wang, J., Dippold, M., Gao, Y., Blagodatskaya, E. y Kuzyakov, Y. 2016. Biochar affects soil organic matter cycling and microbial functions but does not alter microbial community structure in a paddy soil. Science of the Total Environment. 556: 89-97.

Troelstra, S.R., Wagenaar, R., Smant, W. y Peters, B.A.M. 2001. Interpretation of bioassays in the study of interactions between soil organisms and plants: participation of nutrient factors. New Phytology. 150: 697-706.

Valdés, M. 1986. Supervivencia y crecimiento de pinos con ectomicorrizas específicas después de 3 años en un sitio altamente erosionado. Revista Canadiense de Botánica. 64: 885-888.

Vandenkoornhuyse, P., Quaiser, A., Duhamel, M., Le Van, A. y Dufresne, A. 2015. The importance of the microbiome of the plant holobiont. New Phytologist. 206: 1196-1206.

Viollet, A., Pivato, B., Mougel, C., Cleyet-Marel, J.C., GubryRangin, C., Lemanceau, P. y Mazurier, S. 2017. Pseudomonas fluorescens C7R12 type III secretion system impacts mycorrhization of Medicago truncatula and associated microbial communities. Mycorrhiza. 27: 23-33.

Wang, S., Li, T., Zheng, Z. y Chen, H.Y. 2019. Soil aggregateassociated bacterial metabolic activity and community structure in different aged tea plantations. Science of The Total Environment. 654: 1023-1032.

Zheng, W., Morris, E.K. y Rillig, M.C. 2014. Ectomycorrhizal fungi in association with Pinus sylvestris seedlings promote soil aggregation and soil water repellency. Soil Biology and Biochemistry. 78: 326-331. 